\title{
Analysis of Pipe-Roof in Tunnel Exiting Portal by the Foundation Elastic Model
}

\author{
Yanbin Luo, ${ }^{1}$ Jianxun Chen, ${ }^{1}$ Bao Liu, ${ }^{2}$ Lijun Chen, ${ }^{1}$ and Jiangtao Xie ${ }^{1}$ \\ ${ }^{1}$ School of Highway, Chang'an University, Middle-Section of Nan'er Huan Road, Xi'an, Shaanxi Province, China \\ ${ }^{2}$ China Construction Seventh Engineering Division Corp. Ltd., Zhongjian Building, Chengdong Road No. 108, \\ Zhengzhou, Henan, China \\ Correspondence should be addressed to Jianxun Chen; chenjx1969@163.com and Lijun Chen; chenlijun2004@126.com
}

Received 21 April 2017; Revised 1 August 2017; Accepted 17 August 2017; Published 18 October 2017

Academic Editor: Francesco Marotti de Sciarra

Copyright (C) 2017 Yanbin Luo et al. This is an open access article distributed under the Creative Commons Attribution License, which permits unrestricted use, distribution, and reproduction in any medium, provided the original work is properly cited.

\begin{abstract}
The Pasternak double-parameter elastic foundation model of pipe-roof during the construction of tunnel exits is first established. Based on the portal project of Hanjiashan highway tunnel, an inclinometer is adopted to measure the settlement deformation of a pipe-roof and demonstrates the deformation law in tunnel exiting portals. The formulas for calculating the deflection and internal forces are derived to analyze the deformation of the pipe-roof in each excavation stage, and the results are compared with field monitoring data. Finally, the influences of excavation height, excavation footage, and stiffness of the pipe-roof on the support effect are investigated. Analysis indicates that the longitudinal settlement curve shows a groove distribution, which can be divided into five stages: micro, rapid, continuous, resilience, and stable deformation. Moreover, the subsidence rate reaches its maximum at the tunnel face. The influence of tunnel excavation on the deformation mainly has a range of 1.5 times the excavation height. To control the deflection of the pipe-roof, excavation height should be controlled in the range of $3.5 \mathrm{~m}$, excavation footage should be controlled in the range of 1-1.4 m, and the diameter and thickness of the selected pipe-roof should be in the ranges of $89-159 \mathrm{~mm}$ and 5-8 $\mathrm{mm}$, respectively.
\end{abstract}

\section{Introduction}

The rock mass of a tunnel portal is often broken, loose, and weathering and has generally poor geological conditions. Portal excavation can destroy the original balance of a mountain, thus easily generating bedding slipping, collapse, and so on [1-3]. Adopting pipe-roofs is an effective measure extensively applied to overcome the poor stability and slope sliding of heading [4-7]. Many scholars have conducted extensive research on the support mechanism of pipe-roofs, including analytical studies [8-11], field tests $[8,12-14]$, numerical simulations [15-18], and model tests [19-22]. Existing work is mainly aimed at studying the mechanical behaviors of piperoofs in tunnel entry portals. Pipe-roofs are adopted not only in tunnel entry portals, but also in tunnel exiting portals, which have unsatisfactory conditions of eluvium covering and landsides and are adjacent to bridges. The difference in boundary conditions between tunnel entrances and exits leads to differences in the mechanical behaviors of piperoofs. Therefore, it is necessary to take further research on the effects and mechanical behaviors of pipe-roofs during the construction of tunnel exits.

In this paper, the Pasternak double-parameter elastic foundation model of pipe-roof during the construction of tunnel exits is first established, and then, with the Hanjiashan Tunnel of Tongxun Highway as basis, the inclinometer is first adopted to measure the deformation of the pipe-roof in the tunnel exiting portal and the deformation law of the pipe-roof is obtained. Deformation of the pipe-roof in each excavation stage is analyzed and compared with field monitoring data. The accuracy of the calculated model and the theoretical derivation is verified. Finally, the support effect of the pipe-roof in different tunnel excavation heights, excavation footages, and pipe stiffness is investigated. The results can provide a basis for selecting reasonable parameters of pipe-roofs in tunnel exiting portals. 


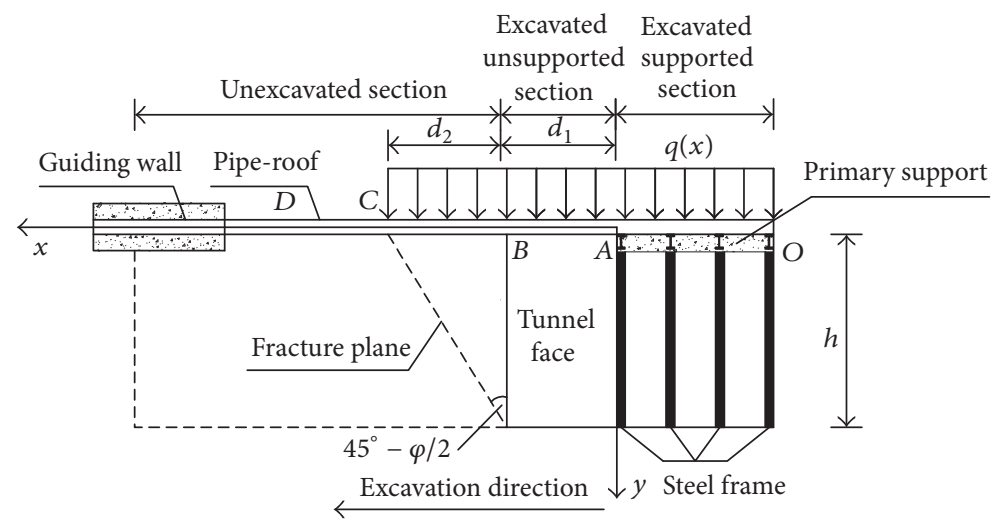

FIGURE 1: Force of pipe-roof in the process of tunnel construction at the exit portal section.

\section{Mechanical Analysis of the Pipe-Roof Deformation}

2.1. Building the Analytical Model. The self-bearing capacity of the rock mass is poor when the tunnel construction is in shallow buried strata. The force of the pipe-roof is definite, and the action between the upper soil and the pipe-roof is not considered. It assumes that the pipe-roof is the straight beam acting on the Pasternak elastic foundation, and the uniform load $q(x)$ of the covering soil acts on the pipe-roof in the excavation section [23]. Owing to the deformation of the rock mass, which begins with the range in front of the tunnel face, the maximum relaxation range of the rock mass is within the range of the fracture plane in front of the tunnel face.

According to the theory of rock mass pressure, the acting range of the longitudinal load of the pipe-roof in front of the tunnel face is $h \cdot\left(\tan 45^{\circ}-\varphi / 2\right)$. Considering the state of the pipe-roof and the rock mass during excavation, the pipe-roof can be divided into four segments in the excavation cycle as shown in Figure 1. (1) The support section $(O A)$ : this section can be assumed as an elastic fixed end with an initial displacement $y_{0}$ and an initial angle $\theta_{0}$. The initial displacement $y_{0}$ of the pipe-roof can be valued as the measured settlement of the crown. (2) The section $(A B)$ without support: the pipe-roof completely bears the pressure $q(x)$ of the upper rock mass. (3) The section $(B C)$ in the disturbance: the pipe-roof is affected not only by the rock mass pressure of $q(x)$ but also by the subgrade reaction $p(x)$. (4) Undisturbed section $(C D)$ : this section only bears the subgrade reaction $p(x)$ between the pipe-roof and the rock mass.

The subgrade reaction can be calculated using the doubleparameter Pasternak model. Based on elastic foundation beam theory, the subgrade reaction and the deflection differential equation of the pipe-roof can be deduced as follows:

$$
\begin{aligned}
& p(x)=k y-G_{p} \frac{d^{2} y}{d x^{2}}, \\
& E I \frac{d y^{4}(x)}{d x^{4}}-G_{p} b^{*} \frac{d y^{2}(x)}{d x^{2}}+k b^{*} y(x)=b q(x) .
\end{aligned}
$$

In the equation, $E$ is the elastic modulus, $G_{p}$ is the shear modulus of the foundation, $I$ is the inertia moment of the pipe-roof, $b^{*}$ is the equivalent width of the beam considering the foundation continuity $b^{*}=b\left[1+\left(G_{p} / k\right)^{1 / 2} / b\right], b$ is the width of the elastic foundation beam (which is equal to the diagram of the pipe-roof), $k$ is the coefficient of the subgrade reaction, and $y(x)$ is the deflection of the pipe-roof.

The elastic foundation beam model of the pipe-roof is divided into two types [24] based on the position of the tunnel face and the pipe-roof. (1) When the tunnel face is far away from the front end of the pipe-roof, the affected area of tunnel excavation does not reach the front end of the pipe-roof, which is considered an infinite elastic foundation beam, as shown in Figure 2(a). (2) When the tunnel face is close to the front end of the pipe-roof, the affected area of tunnel excavation reaches the front end of the pipe-roof, which is considered a finite elastic foundation beam, as shown in Figure 2(b).

In contrast to tunnel exit, guiding wall is installed in the same tunnel entrance and pipe-roof is guided through the reserved hole in the guiding wall, but the excavation direction is converse. The pipe-roofs in tunnel exit and entrance have the same effort in protecting the safety of the tunnel portal construction, but the displayed mechanic effort of them is different. At tunnel exit, the tunnel face starts from inside to outside of the tunnel, the far end of pipe-roof is restrained by the guiding wall, and the corresponding constrained condition at the far end of pipe-roof can be idealized as a fixed support as shown at the point $C$ in Figure 2(b). At tunnel entrance, the tunnel face starts from outside to inside of the tunnel, and the constrained condition at the point $C$ is usually idealized as a hinged support [23].

In addition, it is worth mentioning that the above compared analysis of tunnel exit and entrance have the same precondition, of which the guiding wall is made first and the pipe-roof is constructed from the outside to inside in the tunnel portal. In some instances, the pipe-roof is constructed from the inside to outside and the guiding wall does not need to be set. In this situation, the tunnel exit will be more dangerous than the tunnel entrance. However, this situation is only suitable for the good geological conditions in tunnel portal and is very dangerous for the poor geological conditions. In practice the pipe-roof is usually constructed after finishing the guiding wall in the tunnel portal with weak rock mass and is guided by the reserved hole in the guiding wall. This 


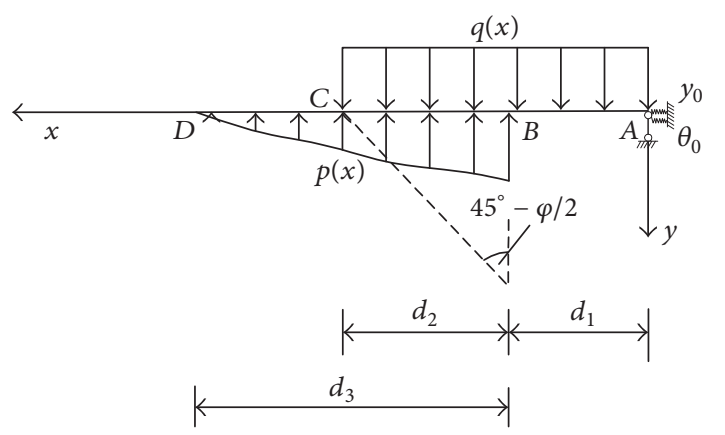

(a) Model A

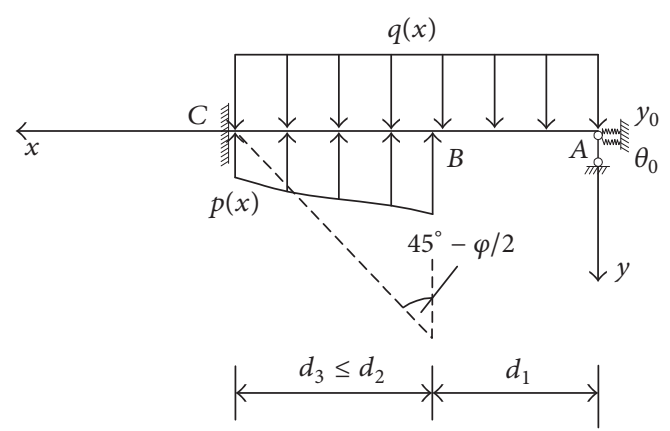

(b) Model B

FIgURE 2: Mechanical model of pipe-roof in the process of tunnel construction at the exit portal section.

situation exists in theory and will not be considered in this paper.

2.2. Solution of Deflection Differential Equation. According to the mechanical calculation model of the pipe-roof, the deflection differential equation in the sections of the piperoof and the corresponding solutions can be calculated depending on elastic foundation beam theory.

2.2.1. Model A. The deflection differential equations in the sections of the pipe-roof are as follows.

(1) Section $A B$. The deflection differential equation in the section of $A B$ is

$$
E I \frac{d^{4} y(x)}{d x^{4}}=b q_{0} .
$$

The corresponding solution can be expressed as

$$
\begin{aligned}
y_{1}(x) & =C_{1} x^{3}+C_{2} x^{2}+C_{3} x+C_{4}+y_{1}{ }^{*}, \\
y_{1}^{*}(x) & =\frac{q_{0}}{24 E I} x^{4} .
\end{aligned}
$$

$C_{1}, C_{2}, C_{3}$, and $C_{4}$ are the undetermined coefficients.

(2) Section $B C$. The deflection differential equation in the section of $B C$ is

$$
E I \frac{d^{4} y(x)}{d x^{4}}-G_{p} b^{*} \frac{d^{2} y(x)}{d x^{2}}+k y(x) b^{*}=b q_{0} .
$$

The corresponding solution can be expressed as

$$
\begin{aligned}
& y_{2}(x) \\
& =e^{\alpha x}\left(C_{5} \cos \beta x+C_{6} \sin \beta x\right) \\
& \quad+e^{-\alpha x}\left(C_{7} \cos \beta x+C_{8} \sin \beta x\right)+y_{2}{ }^{*}, \\
& y_{2}^{*}(x) \\
& =\frac{q}{k b^{*}}\left[1-\cosh \beta\left(x-d_{1}-d_{2}\right) \cos \beta\left(x-d_{1}-d_{2}\right)\right] .
\end{aligned}
$$$$
C_{5}, C_{6}, C_{7} \text {, and } C_{8} \text { are the undetermined coefficients: } \lambda^{4}=
$$$$
k b /(4 E I) ; \alpha=\lambda \sqrt{1+G_{p} \lambda^{2} / k} ; \beta=\lambda \sqrt{1-G_{p} \lambda^{2} / k} \text {. }
$$

(3) Section $C D$. The deflection differential equation in the section of $B C$ is

$$
E I \frac{d^{4} y(x)}{d x^{4}}-G_{p} b^{*} \frac{d^{2} y(x)}{d x^{2}}+k y(x) b^{*}=0 .
$$

The corresponding solution can be expressed as

$$
\begin{aligned}
y_{3}(x)= & e^{\alpha x}\left(C_{5} \cos \beta x+C_{6} \sin \beta x\right) \\
& +e^{-\alpha x}\left(C_{7} \cos \beta x+C_{8} \sin \beta x\right) .
\end{aligned}
$$

Accordingly, the boundary conditions of model A are as follows:

$$
\begin{aligned}
\left.y_{1}\right|_{x=0} & =y_{0}, \\
\left.\theta_{1}\right|_{x=0} & =\left.y_{1}^{(1)}\right|_{x=0}=\theta_{0}, \\
\left.y_{1}\right|_{x=d_{1}} & =\left.y_{2}\right|_{x=d_{1}}, \\
\left.y_{1}^{(2)}\right|_{x=d_{1}} & =\left.y_{2}^{(2)}\right|_{x=d_{1}}, \\
\left.y_{1}^{(1)}\right|_{x=d_{1}} & =\left.y_{2}^{(1)}\right|_{x=d_{1}}, \\
\left.y_{1}^{(3)}\right|_{x=d_{1}} & =\left.y_{2}^{(3)}\right|_{x=d_{1}}, \\
\left.y_{3}\right|_{x \rightarrow \infty} & =0 \\
\left.\theta_{3}\right|_{x \rightarrow \infty} & =0 .
\end{aligned}
$$

The calculation result is $C_{5}=C_{6}=0$. When formulas (3), (6), (7), and (9) and the boundary conditions are used, the following coefficient matrix can be obtained:

$$
\left(\begin{array}{cccccc}
0 & 0 & 0 & 1 & 0 & 0 \\
0 & 0 & 1 & 0 & 0 & 0 \\
d_{1}^{3} & d_{1}^{2} & d_{1} & 1 & P_{35} & P_{36} \\
3 d_{1}^{2} & 2 d_{1} & 1 & 0 & P_{45} & P_{46} \\
6 d_{1} & 2 & 0 & 0 & P_{55} & P_{56} \\
6 & 0 & 0 & 0 & P_{65} & P_{66}
\end{array}\right)\left\{\begin{array}{l}
C_{1} \\
C_{2} \\
C_{3} \\
C_{4} \\
C_{7} \\
C_{8}
\end{array}\right\}=\left\{\begin{array}{l}
y_{0} \\
\theta_{0} \\
\psi_{3} \\
\psi_{4} \\
\psi_{5} \\
\psi_{6}
\end{array}\right\} .
$$


In this matrix,

$$
\begin{aligned}
& P_{35}=-e^{-\alpha d_{1}} \cos (\beta d), \\
& P_{36}=-e^{-\alpha d_{1}} \sin (\beta d) \text {, } \\
& P_{45}=e^{-\alpha d_{1}}[\alpha \cos (\beta d)+\beta \sin (\beta d)], \\
& P_{46}=e^{-\alpha d_{1}}[\alpha \sin (\beta d)-\beta \cos (\beta d)] \text {, } \\
& P_{55}=e^{-\alpha d_{1}}\left[-2 \alpha \beta \sin (\beta d)-\left(\alpha^{2}-\beta^{2}\right) \cos (\beta d)\right] \text {, } \\
& P_{56}=e^{-\alpha d_{1}}\left[2 \alpha \beta \cos (\beta d)-\left(\alpha^{2}-\beta^{2}\right) \sin (\beta d)\right] \text {, } \\
& P_{65}=e^{-\alpha d_{1}}\left[-\left(\beta^{3}-3 \alpha^{2 \beta}\right) \sin (\beta d)\right. \\
& \left.+\left(\alpha^{3}-3 \alpha \beta^{2}\right) \cos (\beta d)\right], \\
& P_{66}=e^{-\alpha d_{1}}\left[\left(\beta^{3}-3 \alpha^{2 \beta}\right) \cos (\beta d)\right. \\
& \left.+\left(\alpha^{3}-3 \alpha \beta^{2}\right) \sin (\beta d)\right], \\
& \psi_{3}=-\frac{q d_{1}^{4}}{24 E I}+\frac{q}{k b^{*}}\left[1-\cos \left(\beta d_{2}\right) \cosh \left(\beta d_{2}\right)\right] \text {, } \\
& \psi_{4}=-\frac{q d_{1}^{3}}{6 E I}+\beta \frac{q}{k b^{*}}\left[\cos \left(\beta d_{2}\right) \sinh \left(\beta d_{2}\right)\right. \\
& \left.-\cosh \left(\beta d_{2}\right) \sin \left(\beta d_{2}\right)\right] \text {, } \\
& \psi_{5}=-\frac{q d_{1}^{2}}{2 E I}+2 \beta^{2} \frac{q}{k b^{*}} \sin \left(\beta d_{2}\right) \sinh \left(\beta d_{2}\right) \text {, } \\
& \psi_{6}=-\frac{q d_{1}}{E I}-2 \beta^{3} \frac{q}{k b^{*}}\left[\cosh \left(\beta d_{2}\right) \sin \left(\beta d_{2}\right)\right. \\
& \left.+\cos \left(\beta d_{2}\right) \sinh \left(\beta d_{2}\right)\right] \text {. }
\end{aligned}
$$

After the preceding process to calculate the undetermined coefficients $C_{1}-C_{8}$ of the deflection equation, the result is introduced in formulas (3), (6), and (9), and the deflection expression of the pipe-roof sections in model $\mathrm{A}$ is determined. The moment, shear force, and rotation angle of the pipe-roof can be obtained based on Bernoulli-Euler theory. The equation is as follows:

$$
\begin{aligned}
& M(x)=-E I \frac{\partial^{2} y}{\partial x^{2}}, \\
& N(x)=\frac{d M}{d x}=-E I \frac{\partial^{3} y}{\partial x^{3}}, \\
& \theta(x)=\frac{d y}{d x} .
\end{aligned}
$$

2.2.2. Model B. The deflection differential equation of sections $A B$ and $C D$ in model $\mathrm{B}$ is similar to the one in model $\mathrm{A}$. Therefore, the solution of the differential equation consists of formulas (3) and (6).
The boundary conditions of model B are as follows:

$$
\begin{aligned}
\left.y_{1}\right|_{x=0} & =y_{0}, \\
\left.\theta_{1}\right|_{x=0} & =\left.y_{1}^{(1)}\right|_{x=0}=\theta_{0}, \\
\left.y_{1}\right|_{x=d_{1}} & =\left.y_{2}\right|_{x=d_{1}}, \\
\left.y_{1}^{(1)}\right|_{x=d_{1}} & =\left.y_{2}^{(1)}\right|_{x=d_{1}}, \\
\left.y_{1}^{(2)}\right|_{x=d_{1}} & =\left.y_{2}^{(2)}\right|_{x=d_{1}}, \\
\left.y_{1}^{(3)}\right|_{x=d_{1}} & =\left.y_{2}^{(3)}\right|_{x=d_{1}}, \\
\left.y_{2}\right|_{x=d_{1}+d_{2}} & =0, \\
\left.y_{2}^{(1)}\right|_{x=d_{1}+d_{2}} & =\left.\theta_{2}\right|_{x=d_{1}+d_{2}}=0 .
\end{aligned}
$$

With formulas (3) and (6) and the boundary conditions, the following coefficient matrix can be obtained:

$$
\begin{gathered}
\left(\begin{array}{cccccccc}
0 & 0 & 0 & 1 & 0 & 0 & 0 & 0 \\
0 & 0 & 1 & 0 & 0 & 0 & 0 & 0 \\
d_{1}^{3} & d_{1}^{2} & d_{1} & 1 & P_{35} & P_{36} & P_{37} & P_{38} \\
3 d_{1}^{2} & 2 d_{1} & 1 & 0 & P_{45} & P_{46} & P_{47} & P_{48} \\
6 d_{1} & 2 & 0 & 0 & P_{55} & P_{56} & P_{57} & P_{58} \\
6 & 0 & 0 & 0 & P_{65} & P_{66} & P_{67} & P_{68} \\
0 & 0 & 0 & 0 & P_{75} & P_{76} & P_{77} & P_{78} \\
0 & 0 & 0 & 0 & P_{85} & P_{86} & P_{87} & P_{88}
\end{array}\right)\left(\begin{array}{c}
C_{1} \\
C_{2} \\
C_{3} \\
C_{4} \\
C_{5} \\
C_{6} \\
C_{7} \\
C_{8}
\end{array}\right) \\
=\left(\begin{array}{c}
y_{0} \\
\theta_{0} \\
\psi_{3} \\
\psi_{4} \\
\psi_{5} \\
\psi_{6} \\
0 \\
0
\end{array}\right) . \\
\end{gathered}
$$

In this matrix,

$$
\begin{aligned}
& P_{35}=-e^{\alpha d_{1}} \cos \left(\beta d_{1}\right), \\
& P_{36}=-e^{\alpha d_{1}} \sin \left(\beta d_{1}\right), \\
& P_{37}=-e^{-\alpha d_{1}} \cos \left(\beta d_{1}\right), \\
& P_{38}=-e^{-\alpha d_{1}} \sin \left(\beta d_{1}\right), \\
& P_{45}=e^{\alpha d_{1}}\left[\beta \sin \left(\beta d_{1}\right)-\alpha \cos \left(\beta d_{1}\right)\right], \\
& P_{46}=-e^{\alpha d_{1}}\left[\alpha \sin \left(\beta d_{1}\right)+\beta \cos \left(\beta d_{1}\right)\right],
\end{aligned}
$$




$$
\begin{aligned}
& P_{47}=e^{-\alpha d_{1}}\left[\alpha \cos \left(\beta d_{1}\right)+\beta \sin \left(\beta d_{1}\right)\right] \text {, } \\
& P_{48}=e^{-\alpha d_{1}}\left[\alpha \sin \left(\beta d_{1}\right)-\beta \cos \left(\beta d_{1}\right)\right] \text {, } \\
& P_{55}=e^{\alpha d_{1}}\left[2 \alpha \beta \sin \left(\beta d_{1}\right)+\left(\beta^{2}-\alpha^{2}\right) \cos \left(\beta d_{1}\right)\right] \text {, } \\
& P_{56}=e^{\alpha d_{1}}\left[\left(\beta^{2}-\alpha^{2}\right) \sin \left(\beta d_{1}\right)-2 \alpha \beta \cos \left(\beta d_{1}\right)\right] \text {, } \\
& P_{57}=e^{-\alpha d_{1}}\left[-2 \alpha \beta \sin \left(\beta d_{1}\right)+\left(\beta^{2}-\alpha^{2}\right) \cos \left(\beta d_{1}\right)\right] \text {, } \\
& P_{58}=e^{-\alpha d_{1}}\left[\left(\beta^{2}-\alpha^{2}\right) \sin \left(\beta d_{1}\right)+2 \alpha \beta \cos \left(\beta d_{1}\right)\right] \text {, } \\
& P_{65}=e^{\alpha d_{1}}\left[\left(-\beta^{3}+3 \alpha^{2} \beta\right) \sin \left(\beta d_{1}\right)\right. \\
& \left.+\left(3 \alpha \beta^{2}-\alpha^{3}\right) \cos \left(\beta d_{1}\right)\right], \\
& P_{66}=e^{\alpha d_{1}}\left[\left(\beta^{3}-3 \alpha^{2} \beta\right) \cos \left(\beta d_{1}\right)\right. \\
& \left.+\left(3 \alpha \beta^{2}-\alpha^{3}\right) \sin \left(\beta d_{1}\right)\right] \text {, } \\
& P_{67}=e^{-\alpha d_{1}}\left[\left(-\beta^{3}+3 \alpha^{2} \beta\right) \sin \left(\beta d_{1}\right)\right. \\
& \left.+\left(\alpha^{3}-3 \alpha \beta^{2}\right) \cos \left(\beta d_{1}\right)\right], \\
& P_{68}=e^{-\alpha d_{1}}\left[\left(\beta^{3}-3 \alpha^{2} \beta\right) \cos \left(\beta d_{1}\right)\right. \\
& \left.+\left(\alpha^{3}-3 \alpha \beta^{2}\right) \sin \left(\beta d_{1}\right)\right], \\
& P_{75}=e^{\alpha\left(d_{1}+d_{2}\right)} \cos \left[\beta\left(d_{1}+d_{2}\right)\right], \\
& P_{76}=e^{\alpha\left(d_{1}+d_{2}\right)} \sin \left[\beta\left(d_{1}+d_{2}\right)\right], \\
& P_{77}=e^{-\alpha\left(d_{1}+d_{2}\right)} \cos \left[\beta\left(d_{1}+d_{2}\right)\right], \\
& P_{78}=e^{-\alpha\left(d_{1}+d_{2}\right)} \sin \left[\beta\left(d_{1}+d_{2}\right)\right], \\
& P_{85}=e^{\alpha\left(d_{1}+d_{2}\right)}\left\{\alpha \cos \left[\beta\left(d_{1}+d_{2}\right)\right]\right. \\
& \left.-\beta \sin \left[\beta\left(d_{1}+d_{2}\right)\right]\right\}, \\
& P_{86}=e^{\alpha\left(d_{1}+d_{2}\right)}\left\{\alpha \sin \beta\left[\beta\left(d_{1}+d_{2}\right)\right]\right. \\
& \left.+\beta \cos \left[\beta\left(d_{1}+d_{2}\right)\right]\right\}, \\
& P_{87}=e^{-\alpha\left(d_{1}+d_{2}\right)}\left\{-\alpha \cos \left[\beta\left(d_{1}+d_{2}\right)\right]\right. \\
& \left.-\beta \sin \left[\beta\left(d_{1}+d_{2}\right)\right]\right\}, \\
& P_{88}=e^{-\alpha\left(d_{1}+d_{2}\right)}\left\{-\alpha \sin \left[\beta\left(d_{1}+d_{2}\right)\right]\right. \\
& \left.+\beta \cos \beta\left[\beta\left(d_{1}+d_{2}\right)\right]\right\}, \\
& \psi_{3}=-\frac{q d_{1}^{4}}{24 E I}+\frac{q}{k b^{*}}\left[1-\cos \left(\beta d_{2}\right) \cosh \left(\beta d_{2}\right)\right] \text {, } \\
& \psi_{4}=-\frac{q d_{1}^{3}}{6 E I}+\beta \frac{q}{k b^{*}}\left[\sinh \left(\beta d_{2}\right) \cos \left(\beta d_{2}\right)\right. \\
& \left.-\cosh \left(\beta d_{2}\right) \sin \left(\beta d_{2}\right)\right] \text {, }
\end{aligned}
$$

$$
\begin{aligned}
\psi_{5} & =-\frac{q d_{1}^{2}}{2 E I}+2 \beta^{2} \frac{q}{k b^{*}} \sinh \left(\beta d_{2}\right) \sin \left(\beta d_{2}\right), \\
\psi_{6} & =-\frac{q d_{1}}{E I}-2 \beta^{3} \frac{q}{k b^{*}}\left[\cosh \left(\beta d_{2}\right) \sin \left(\beta d_{2}\right)\right. \\
& \left.+\sinh \left(\beta d_{2}\right) \cos \left(\beta d_{2}\right)\right] .
\end{aligned}
$$

After the preceding process to calculate the undetermined coefficients $C_{1}-C_{8}$ of the deflection equation, the result is introduced in formulas (3) and (6), and the deflection expression of the pipe-roof sections in model $\mathrm{B}$ is determined. Then the moment, shear force, and rotation angle of the piperoof can be obtained.

\section{Engineering Case Analysis}

3.1. General Situation of Construction. Hanjiashan tunnel of the Tongchuan-Xunyi expressway is located in the northwest of Tuqiao Yaoshang village in Xunyi county, extending from the northeast to the southeast. The tunnel has a design speed of $80 \mathrm{~km} / \mathrm{h}$ and is bidirectional in four lanes. The left line is $885 \mathrm{~m}$ with a maximum buried depth of $123 \mathrm{~m}$, and the right line is $865 \mathrm{~m}$ with a maximum buried depth of $142 \mathrm{~m}$. The entrance and exit of the tunnel are located in the slope zone; the exit in particular lies on a steep terrain. The slope of the left exit reaches $25^{\circ}-40^{\circ}$ and mainly comprises residual silty clay, fully weathered sandstone, conglomerate, and mudstone. The entrance and exit of the tunnel easily collapse with the occurrence of strong rainfall or construction disturbance.

Road construction was difficult because of the geological and topographic conditions of the tunnel exit. In addition, the tunnel exit is adjacent to the bridge, making it inconvenient to adopt big machines and equipment. Therefore, a oneway construction plan was adopted, wherein the tunnel was excavated to transfixion from a substantial pile number to a small one. The advanced pipe-roof was to be constructed starting from the inside to outside. In this way, the topography obstacle of the tunnel exit was overcome while avoiding destruction of the ecological environment caused by the road construction in a steep slope. However, compared with the entrance project, the pipe-roof method employed in the tunnel exiting portal was more conducive for maintaining a safe and steady slope. The original design was also optimized to ensure construction progress and safety. The specific support parameters are shown in Figure 3. In order to ensure construction safety during the tunnel exit, the three benches and seven steps excavation method was adopted. The excavation span is $12.78 \mathrm{~m}$ and the excavation height is $9.28 \mathrm{~m}$. The excavation footage is $0.5 \mathrm{~m}$ which is in accord with the longitudinal space of steel frame.

\subsection{Field Measurement of the Pipe-Roof}

3.2.1. Measurement Arrangement. The tunnel exit was chosen as the test section for measuring the deformation of the pipe-roof in the tunnel exiting portal because of its poor topographic conditions. A CX-4C inclinometer was used to measure the deformation of the pipe-roof in the tunnel 


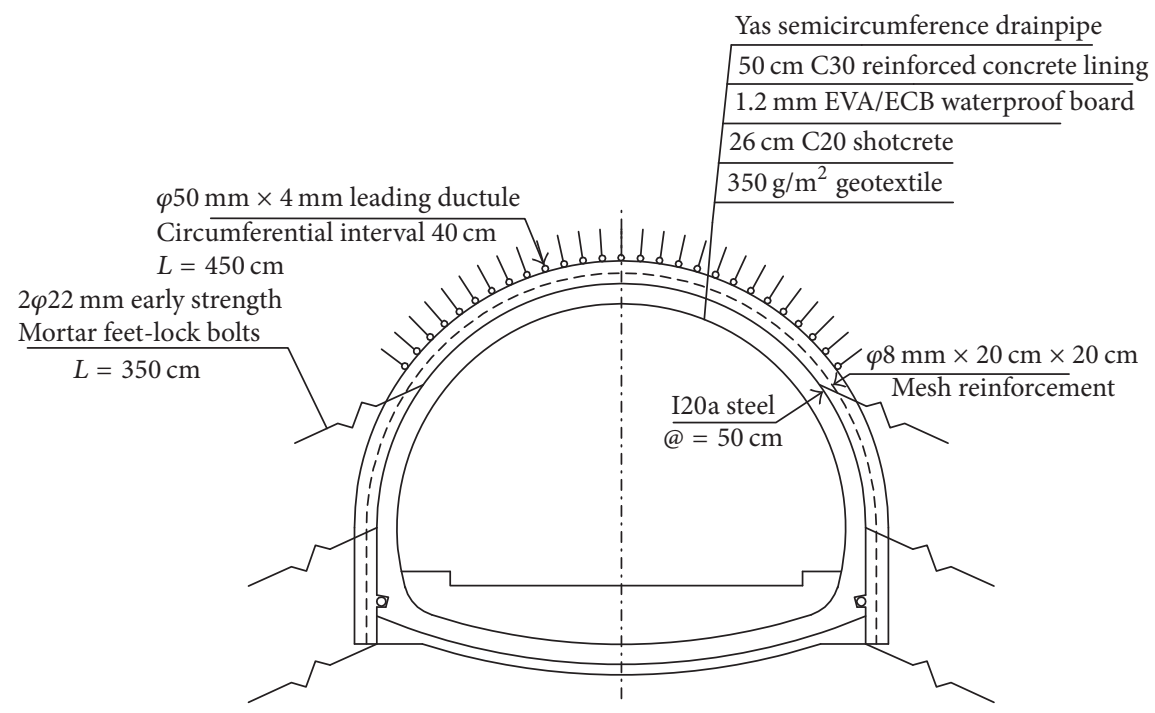

(a) Transversal lining design

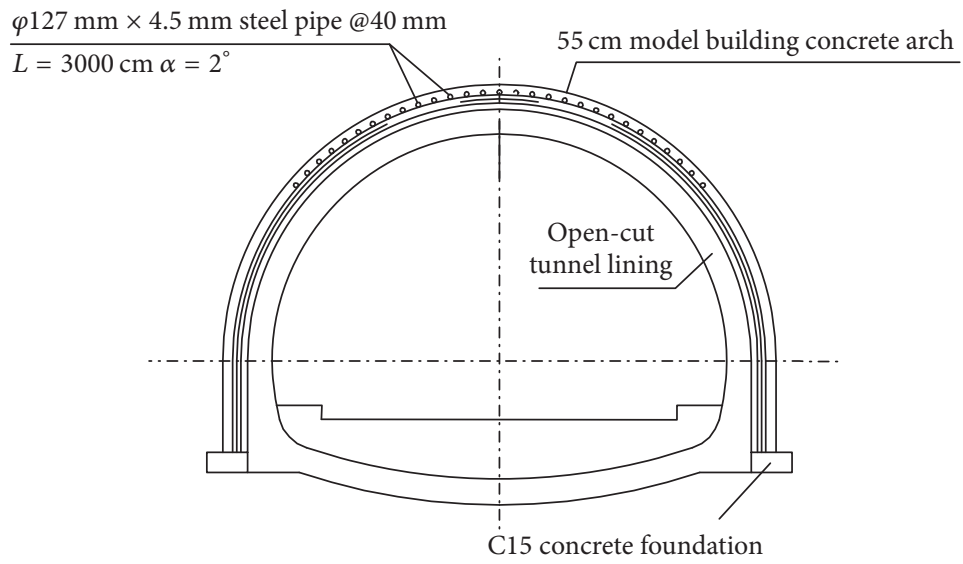

(b) Transversal pipe-roof design

FIGURE 3: Design of tunnel exiting portal.

exiting portal. This inclinometer has high precision, good stability, high repeatability, and small drift. It is also convenient to operate and its monitoring data are reliable.

An inclinometer was buried in the crown of the number 16 and number 6 holes of the pipe-roof. The effective measurement range of each inclinometer is $20 \mathrm{~m}$. The settlement datum was set in each orifice of the inclinometer, measuring one point per $0.5 \mathrm{~m}$. The longitudinal and lateral arrangements of the inclinometer tube are shown in Figures 4 and 5.

The inclinometer was buried after pipe-roof installation and before grouting. The burying steps were as follows. (1) The pole was cleaned to put the inclinometer in the pipes. (2) The inclinometer was placed in the pipes by using a plumb to control the direction and vertically adjusting a set of guide. The grouting tube and the inclinometer were put together to successfully put the grouting tube in the pipes. While connecting the inclinometers, muck should be avoided from blocking the guide. The pipes were fixed using screws and gluing them down to prevent the slurry from blocking the inclinometer and the guide. (3) The orifice was temporarily sealed and the pipe ends were warped using wet geotextile to avoid burning the inclinometer while welding. The guide tube was extended to ensure the precise position of the inclinometer orifice and for easy sealing. (4) The piperoof was grouted. (5) The guide tube was cut off after the initial setting while ensuring that the inclinometer was not damaged. The inclinometer end was smoothened.

The initial value should usually be measured twice or three times, with the steady one chosen as the reference value. The coordinate of the inclinometer orifice is taken as the datum. When every measurement was carried out, the instrument probe was put in the inclinometer with a PVC tube measuring one point per $0.5 \mathrm{~m}$ to the bottom of the hole. The difference of the measured value subtracted from the initial one was the measured displacement $\Delta Y=Y_{m}-Y_{i}$.

3.2.2. Analysis of Measured Results. The measurement lasted from January 2015 to March 2015. Two holes were arranged to measure the deformation of the pipe-roof on the basis of the plan. As the number 6 hole was damaged, only the measuring 


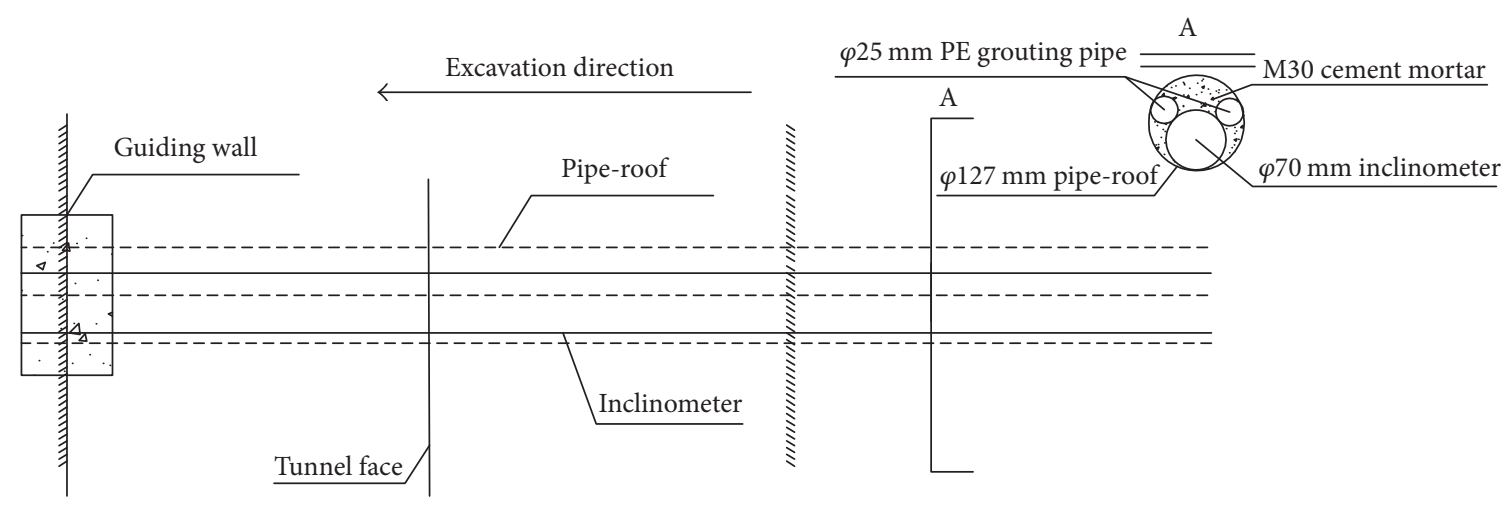

FIGURE 4: The longitudinal arrangement of inclinometer tube.

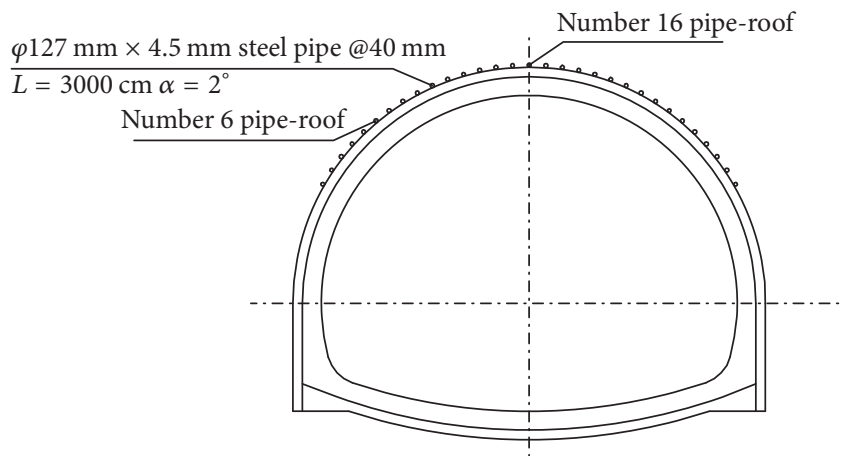

FIGURE 5: The lateral arrangement of inclinometer tube.

data of the number 16 hole was analyzed for regular change. The specific measured results and analyses are as in Figures 6-8.

Figure 6 shows that the settlement of the pipe-roof increases along with the excavation. First, the deformation dramatically increases and then gradually stabilizes with the construction of the initial support. The vertical displacement of the umbrella arch in the range of $1-2 \mathrm{~m}$ of the tunnel is positive. The pipe-roof appears to trace upward in this range. This result shows that the umbrella plays an important role as an end constraint in the tunnel exiting portal. Therefore, the umbrella arch is vital for setting up the pipe-roof advanced support system because it stabilizes the slope and controls the entire settlement of the pipe-roof. The cumulative curve of the pipe-roof settlement is concave, where both ends are small and the middle part is large. This outcome is attributed to the tunnel face moving toward the portal and the settlement of the pipe-roof accumulating in space and time. The main reason is that, on one hand, one end of the pipe-roof is constrained by the umbrella arch, the other end is put on the stable support, and the force model of the pipe-roof is approximated as the restrained beam with two ends. The measurement result shows the deformation of the tunnel initial support. Meanwhile, when monitoring of the deformation of the pipe-roof began, the vault settlement of the pipe-roof end put on the initial support was stable. On the other hand, the tunnel was excavated in the pile number

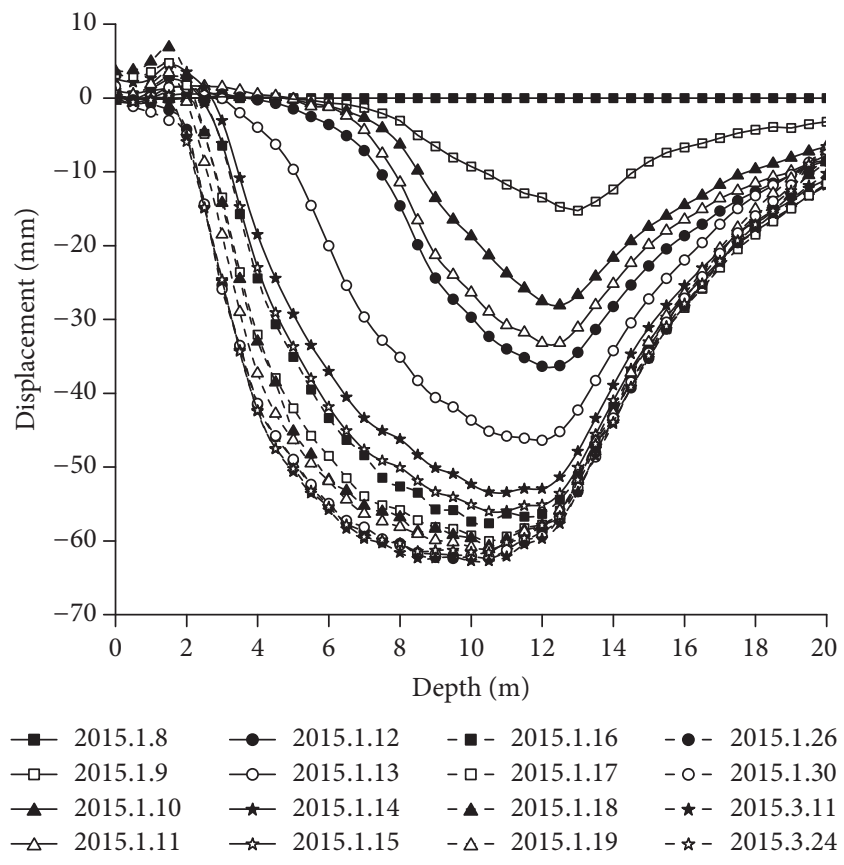

Figure 6: Cumulative curve of pipe-roof settlement.

of the $14 \mathrm{~m}$ measured point when monitoring began. This resulted in the partial displacement of the measured point at 14-20 m depth, leading to the loss of measured displacement and causing the settlement of the measured point at 10-20 m depth to be less than the one at $0-10 \mathrm{~m}$ depth.

Figure 7 shows that the settlement time curve of the piperoof settlement can be divided into five stages: (1) Micro Deformation. When the tunnel face is near the measured point, the settlement of the pipe-roof is small. (2) Rapid Deformation. When the upper bench is excavated, the settlement of the pipe-roof rapidly increases, the tunnel face is near the section of the measured point, and the settlement rate reaches a maximum. (3) Continuous Deformation. When the middle bench is excavated, the settlement of the piperoof continually increases and then slows with the initial support of the tunnel and the pipe-roof bearing the rock mass pressure together. (4) Resilience Deformation. When the invert is backfilled, the tunnel face passes through a length of 


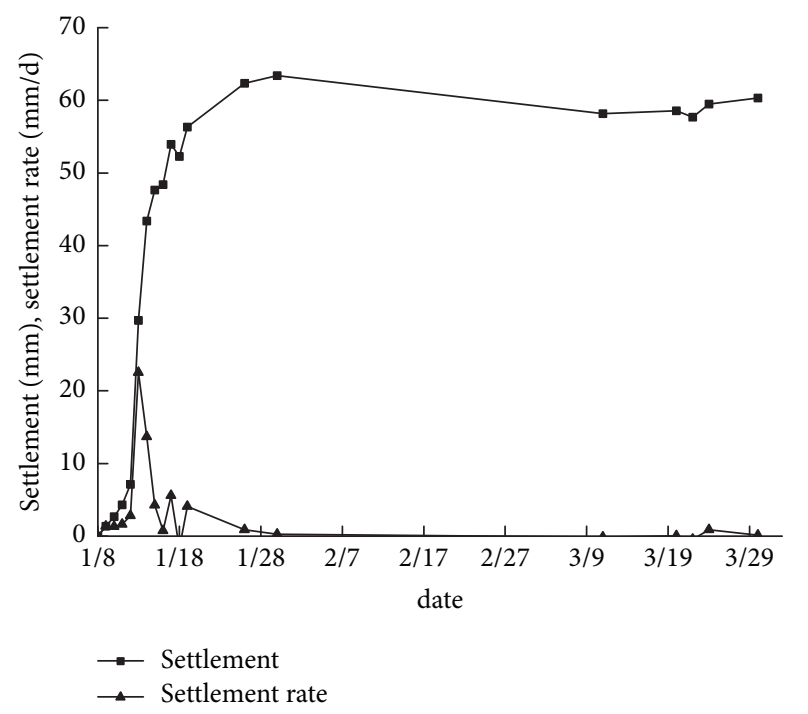

FIGURE 7: The settlement time curve of pipe-roof measuring point at the depth of $7 \mathrm{~m}$.

a section of the measured point and the deformation of the pipe-roof rebound emerges with micro resilience. This effect is attributed to the support structure, which is in a state of elasticity with the protection of the pipe-roof. Furthermore, this phenomenon shows the well-advanced support action of the pipe-roof. (5) Stable Deformation. When the initial support encloses for a while, the settlement of the pipe-roof tends to stabilized. At this time, the stability of the rock mass is a result of the combined work of the pipe-roof and the initial support. The advanced support action of the pipe-roof is basically completed.

Figure 8 shows that the ratio of the accumulated settlement accounting for the total settlement gradually decreases with the increase of depth of the inclinometer measured point, which is farther from the portal. When the tunnel face is close to the shallow measured point near the portal, the pipe-roof appears to trace upward. This is attributed to the measured points which are close to the umbrella arch, in which the umbrella arch plays an important role as an end constraint. The settlement of the pipe-roof in the tunnel face is large; therefore, elastic deformation appears in the piperoof. The excavation range that influences the deformation of the pipe-roof in front of the tunnel face is 1.5 times that of the excavation height $(2 \mathrm{~m})$. With the increase in measured depth, the end constraint effect of the pipe-roof gradually weakens. Meanwhile, the increase in buried depth enlarges the range in which the excavation influences the deformation of the pipe-roof in front of the tunnel face. However, the influence range is still $3 \mathrm{~m}$ in front of the tunnel face, which is 1.5 times that of the excavation height.

3.3. Model Validation. According to the engineering characteristics of the Hanjiashan Tunnel, the parameters of the rock mass are as follows: coefficient of the subgrade reaction $k=40000 \mathrm{kN} / \mathrm{m}^{3}$, shear modulus of the foundation $G_{p}=$ $10000 \mathrm{kN} / \mathrm{m}$, bulk density $=20 \mathrm{kN} / \mathrm{m}^{3}$, internal friction angle $\varphi=22^{\circ}$, single pipe combined modulus $E_{p}=47.26 \mathrm{GPa}$, single pipe combined inertial moment $I_{p}=12.77 \times 10^{6} \mathrm{~mm}^{4}$, and tunnel excavation height $h=2 \mathrm{~m}$. Two steel frames are supported in each cycle, with a $50 \mathrm{~cm}$ spacing between frames. Therefore, the excavation footage $d_{1}$ is $1.2 \mathrm{~m}$.

3.3.1. Model A. When the pile of the tunnel excavation is $9 \mathrm{~m}$ away from the orifice, the vertical rock mass pressure of the pipe-roof is $q=140 \mathrm{kPa}$. The initial vertical displacement of the pipe-roof and the initial support connecting end $y_{0}=$ $10 \mathrm{~mm}$. The initial angle of the pipe-roof is $\theta_{0}=1.5^{\circ}$ because the pipe-roof is far away from the umbrella arch. The deflection curves of the pipe-roof are calculated by MATLAB and compared with the measured values, as shown in Figure 9.

The comparison between the calculated results and the measured data shows the following.

(1) The deflection curve of the pipe-roof is in good agreement with the measured one, which shows the correctness of the theoretical calculation. The differences between the theoretical calculations and the measured results are mainly attributed to the hypothesis that the soil is a uniformly continuous elastomer in theoretical calculation. Moreover, the soil is anisotropic and heterogeneous in construction.

(2) The range in which the excavation influences the deformation of the pipe-roof in front of the tunnel face is $3 \mathrm{~m}$, which is 1.5 times that of the height of the tunnel excavation and is in good agreement with the measured results.

(3) The maximum deflection of the pipe-roof is $25.6 \mathrm{~mm}$, which occurred near the tunnel face. The reason is that the area was excavated without support, and thus the pipe-roof bears all the rock mass pressure and the deformation reaches the maximum. This area is also the most critical in tunnel excavation resulting from the largest deformation.

3.3.2. Model B. The distance between the tunnel face and the fracture plane is almost $d_{2}=h \cdot \tan \left(45^{\circ}-\varphi / 2\right)=1.35 \mathrm{~m}$, in which model $\mathrm{B}$ is adopted when the distance between the tunnel face and the umbrella arch is less than $1.35 \mathrm{~m}$. When the tunnel face is $1.35 \mathrm{~m}$ away from the umbrella arch, the vertical uniform rock mass pressure of the pipe-roof is $q=$ $50 \mathrm{kPa}$. The initial vertical displacement of the pipe-roof and the initial support connecting end is $y_{0}=10 \mathrm{~mm}$. The initial angle of the pipe-roof is $\theta_{0}=1^{\circ}$ because the pipe-roof is close to the umbrella arch. The deflection curves of the pipe-roof are calculated by MATLAB and compared with the measured values, as shown in Figure 10.

The comparison between the calculated results and the measured data shows the following:

(1) The deflection curve of the pipe-roof is in good agreement with the measured one, which shows the accuracy of the theoretical calculation.

(2) The range in which the excavation influences the deformation of the pipe-roof in front of the tunnel face is $3 \mathrm{~m}$.

(3) The maximum deflection of the pipe-roof is $21.5 \mathrm{~mm}$, which occurred near the tunnel face.

From the preceding analysis, the deformation of the piperoof relates to the mechanical parameters of the rock mass and the pipe-roof, as well as the excavation position, the footage, and the excavation height. 


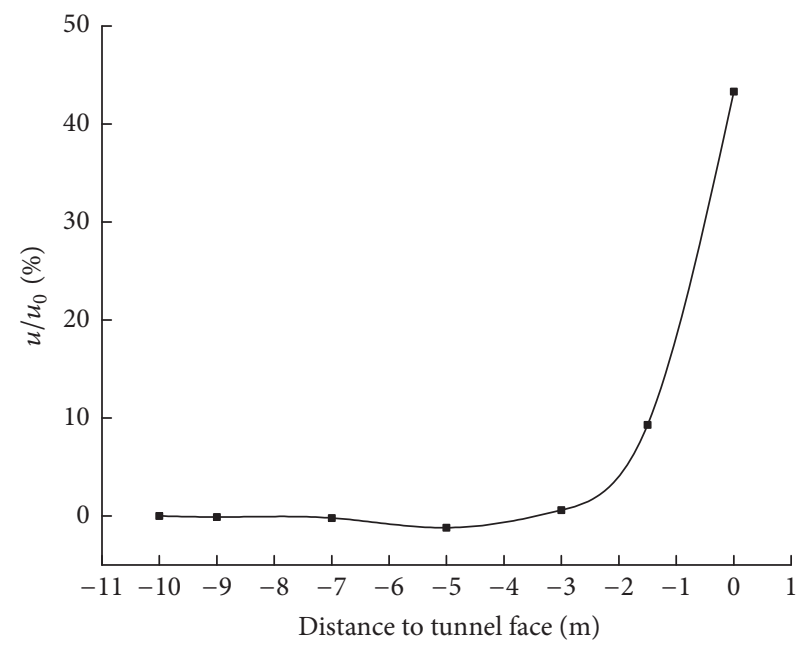

(a) At 4 m depth

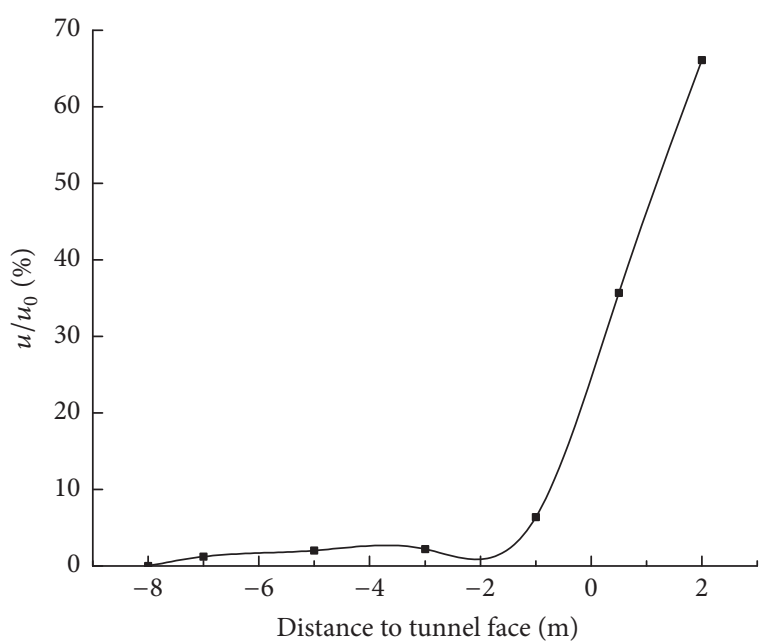

(b) At $6 \mathrm{~m}$ depth

FIGURE 8: The settlement space curves of pipe-roof measuring point at the different depth.

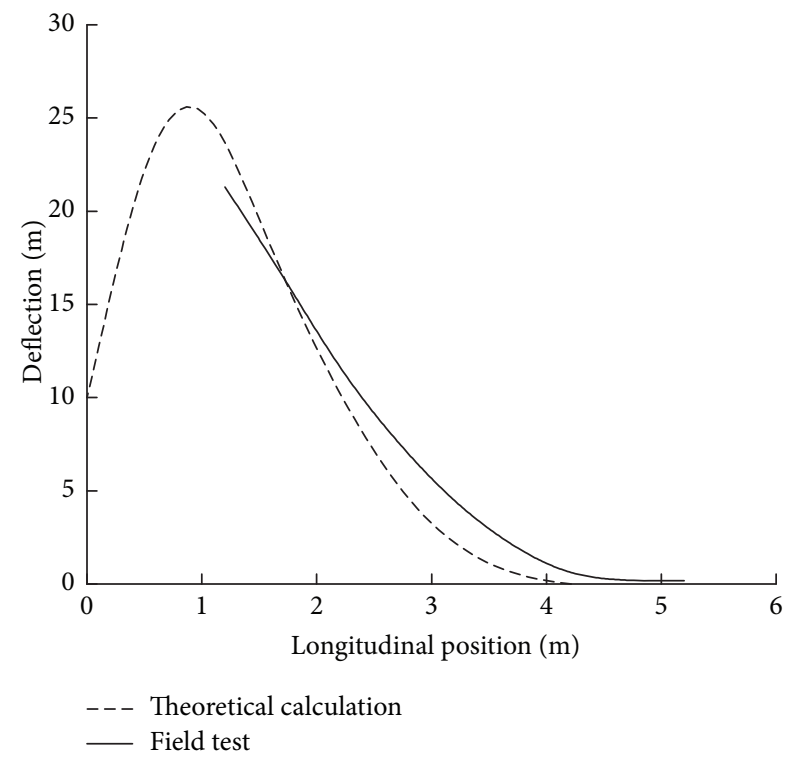

Figure 9: Comparison of calculated values and measured one of pipe-roof deflection in model A.

\subsection{Parameters Analysis}

3.4.1. Excavation Height. The excavation height values are $h=$ $2,2.5,3,3.5,4$, and $4.5 \mathrm{~m}$. The deflection curves of different excavation heights in model A are shown in Figure 11(a). The variation curve of the maximum deflection of different excavation heights is shown in Figure 11(b).

Figure 11 shows the following:

(1) The deflection of the pipe-roof increases with the increase in excavation height of the tunnel face. When $h$ is between 2 and $3.5 \mathrm{~m}$, the excavation height has a slight effect on the deformation of the pipe-roof; when $h$ is larger than $3.5 \mathrm{~m}$, the deformation of the pipe-roof sharply increases with

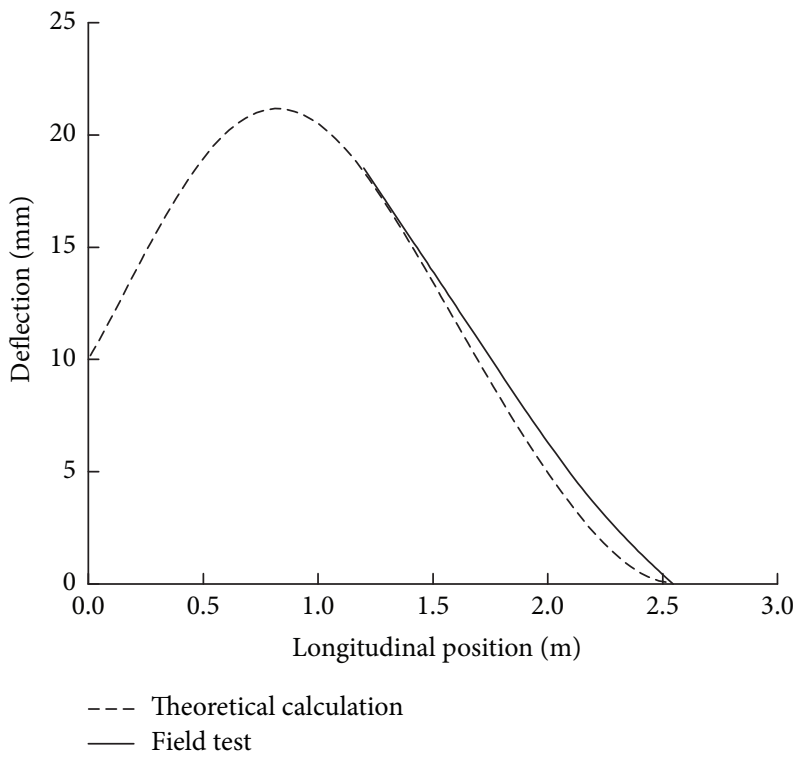

Figure 10: Comparison of calculated values and measured one of pipe-roof deflection in model B.

the increase in excavation height. Therefore, the excavation height should be controlled in the range of $3.5 \mathrm{~m}$.

(2) The maximum deflection of the pipe-roof appears near the tunnel face.

(3) The range in which excavation influences the deformation of the pipe-roof in front of the tunnel face increases with the increase in excavation height, and the range is 1.5 times that of the excavation height.

3.4.2. Excavation Footage. The excavation footage values are $d_{1}=0.6,0.8,1.0,1.2,1.4$, and $1.6 \mathrm{~m}$. The deflection curves of different excavation footages in model A are shown in 


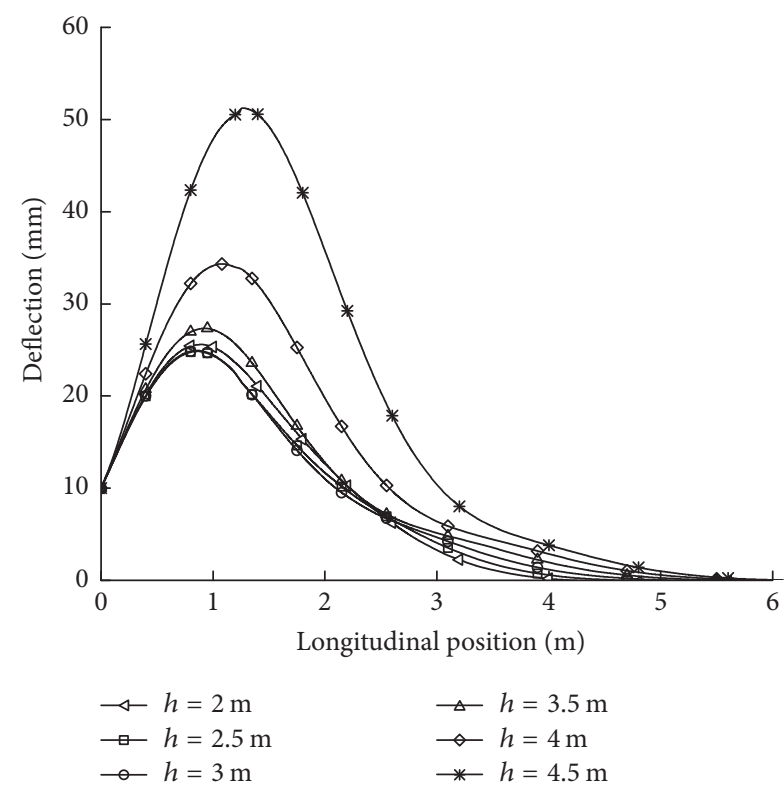

(a) Deflection with different excavation height

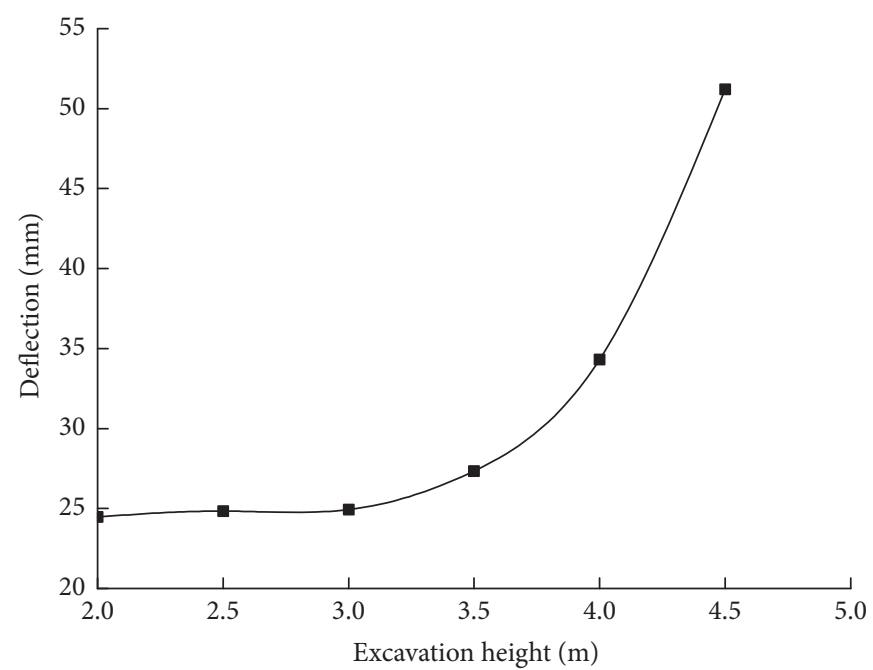

(b) The maximum deflection with excavation height

FIGURE 11: Variation curve of pipe-roof deflection with tunnel excavation height.

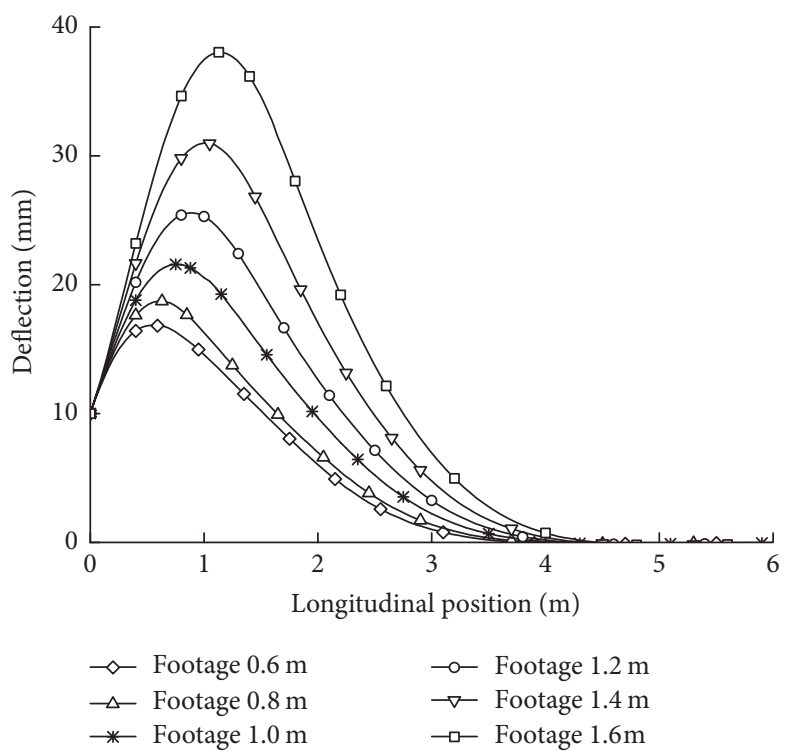

(a) Deflection with different excavation

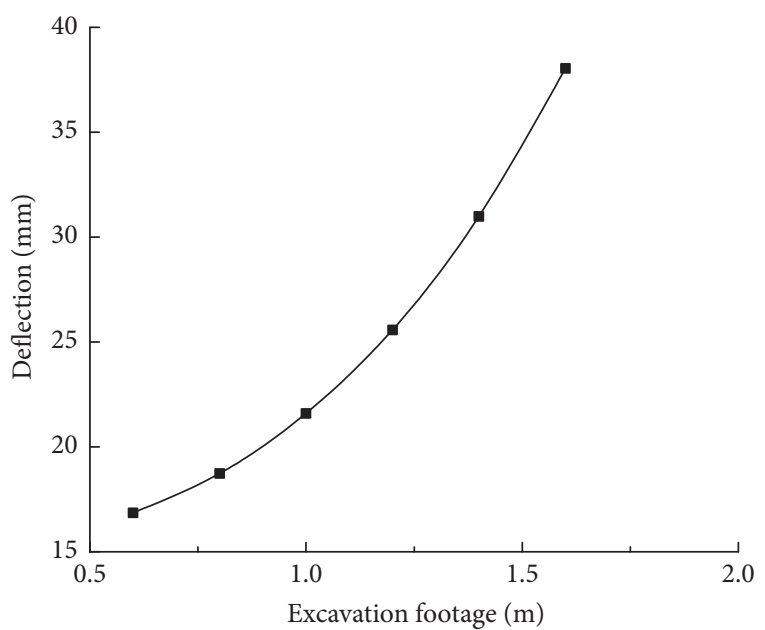

(b) The maximum deflection with excavation

FIGURE 12: Variation curve of pipe-roof deflection with tunnel excavation footage.

Figure 12(a). The variation curve of the maximum deflection of different excavation footages is shown in Figure 12(b).

Figure 12 shows the following:

(1) The deflection of the pipe-roof increases with the increase in excavation footage of the tunnel face. The increase rate also rises. Therefore, the excavation footage should be controlled in the range of 1-1.4 m.

(2) The maximum deflection of the pipe-roof appears near the tunnel face.

(3) The range in which the excavation influences the deformation of the pipe-roof in front of the tunnel face increases with the increase in excavation footage, and the range is 1.5 times that of the excavation height.

3.4.3. Pipe Diameter. According to the common size of the pipe-roof (as shown in Table 1), the deflection curves of the different pipe diameters in model $\mathrm{A}$ are shown in Figure 13(a). The variation curve of the maximum deflection of the different pipe diameters is shown in Figure 13(b).

Figure 13 shows the following:

(1) When the pipe diameter is less than $108 \mathrm{~mm}$, the deflection of the pipe-roof significantly increases with the 


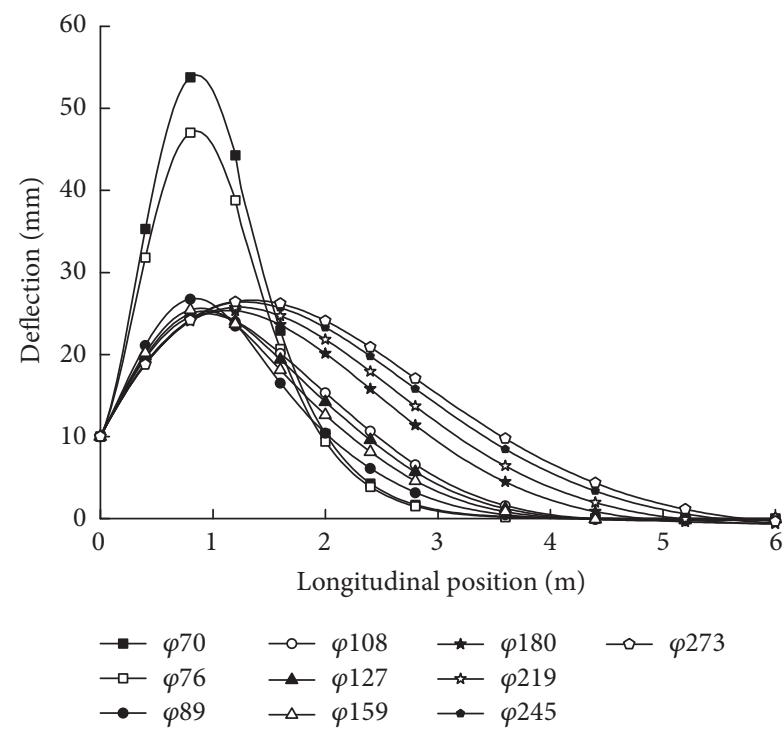

(a) Pipe-roof deflection with diameters

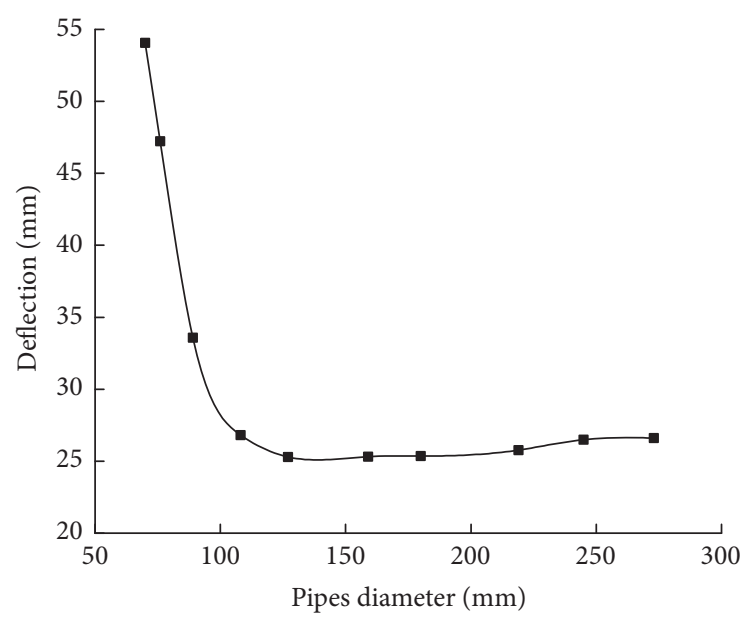

(b) The maximum deflection with diameters

FIGURE 13: Variation curve of pipe-roof deflection with the diameters.

TABLE 1: Common sizes of steel pipe for pipe-roof.

\begin{tabular}{lcc}
\hline $\begin{array}{l}\text { Pipe-roof } \\
\text { diameter }(\mathrm{mm})\end{array}$ & Thickness $(\mathrm{mm})$ & $\begin{array}{c}\text { Single pipe combined stiffness } \\
\left(\mathrm{N} / \mathrm{m}^{2}\right)\end{array}$ \\
\hline 70 & 4.5 & $7.8 \times 10^{4}$ \\
76 & 5 & $1.1 \times 10^{5}$ \\
89 & 5 & $1.9 \times 10^{5}$ \\
108 & 6 & $4.0 \times 10^{5}$ \\
127 & 7 & $7.7 \times 10^{5}$ \\
159 & 8 & $1.8 \times 10^{6}$ \\
180 & 8 & $2.7 \times 10^{6}$ \\
219 & 10 & $5.7 \times 10^{6}$ \\
245 & 10 & $9.0 \times 10^{6}$ \\
273 & 10 & $1.3 \times 10^{7}$ \\
\hline
\end{tabular}

decreasing pipe diameter; when the pipe diameter is more than $108 \mathrm{~mm}$, the pipe diameter of the pipe-roof has a slight effect on deflection, which may explain why the $\varphi 108 \times 6 \mathrm{~mm}$ pipe is extensively used in engineering. This finding also shows that the diameter range of $89-159 \mathrm{~mm}$ and thickness range of $5-8 \mathrm{~mm}$ for the steel pipes usually selected are reasonable.

(2) The maximum deflection of the pipe-roof appears near the tunnel face.

(3) The influencing area of the tunnel excavation on the pipe-roof in front of the tunnel face first decreases and then increases with the increase in pipe diameter. When the pipe diameter is less than $245 \mathrm{~mm}$, the range in which the excavation influences the deformation of the pipe-roof in front of the tunnel face is less than two times that of the excavation height. When the pipe diameter is more than $245 \mathrm{~mm}$, the range in which the excavation influences the deformation of the pipe-roof in front of the tunnel face is more than two times that of the excavation height.

\section{Conclusion}

Through the theoretical analysis of the pipe-roof deformation and the field test in the tunnel exiting portal, the following conclusions can be drawn.

(1) The measurement result shows that adopting an incliinclinometernometer to measure the deformation of the pipe-roof is feasible. The longitudinal settlement curve of the pipe-roof shows a groove distribution. The ratio of the accumulated settlement accounting for the total settlement gradually decreases with the increase in depth of the measured point. The time curve of the settlement can be divided into five stages: micro deformation, rapid deformation, continuous deformation, resilience deformation, and stable deformation. The subsidence rate of the pipe-roof reaches the maximum near the tunnel face. The influence of tunnel excavation on the deformation of the pipe-roof mainly focuses on the range of 1.5 times that of the tunnel excavation height.

(2) The comparison of the theoretical analysis and the file test data shows that adopting the double-parameter Pasternak elastic foundation beam model to calculate the deformation of the pipe-roof in the tunnel exiting portal is feasible. The maximum settlement of the pipe-roof appears near the tunnel face and in different positions with the variation of excavation height, footage, and stiffness of the pipes. The deflection of the pipe-roof increases with the increase in excavation height; therefore, the tunnel excavation height should be controlled in the range of $3.5 \mathrm{~m}$. The deflection of the pipe-roof increases with the increase in excavation footage; hence, the footage should be controlled in the range of 1-1.4 m. The enlargement effect on the stiffness of the pipes to reduce deflection is limited; therefore, diameter and thickness of the selected 
pipes should be in the range of $89-159 \mathrm{~mm}$ and $5-8 \mathrm{~mm}$, respectively.

\section{Conflicts of Interest}

The authors declare that they have no conflicts of interest.

\section{Acknowledgments}

The authors would like to acknowledge the financial support provided by the National Natural Science Fund Project of China (Grants nos. 51108034, 51408054, and 51678063), the China Postdoctoral Science Foundation (Grant no. 2016M602738), the Natural Science Basic Research Plan of Shaanxi Province (Grant no. 2017JM5051), the Science and Technology Coordinating Innovative Engineering Project of Shaanxi Province (Grant no. 2014KTCG01-02), the Key Science and Technology Innovation Team Program of Shaanxi Province (Grant no. 2014KCT-29), and the Chang Jiang Scholars Program (Grant no. T2014214).

\section{References}

[1] J. Lai, S. Mao, J. Qiu et al., "Investigation progresses and applications of fractional derivative model in geotechnical engineering," Mathematical Problems in Engineering, vol. 2016, Article ID 9183296, 15 pages, 2016.

[2] L. P. Li, T. Lei, S. C. Li, Z. H. Xu, Y. G. Xue, and S. S. Shi, "Dynamic risk assessment of water inrush in tunnelling and software development," Geomechanics and Engineering, vol. 9, no. 1, pp. 57-81, 2015.

[3] Y. Luo, J. Chen, W. Xi et al., "Analysis of tunnel displacement accuracy with total station," Measurement, vol. 83, pp. 29-37, 2016.

[4] C. Z. Ji, G. K. Zhai, and W. Zhu, "Application of Tube Frame in Tunnel Construction in Soft Wall Rocks," Journal of XIAN Highway University, vol. 19, no. S1, pp. 39-40, 1999.

[5] H. J. Xing and Z. X. Xu, "Application of big pipe roof in largespan shallow buried tunnel engineering," Chinese Journal of Rock Mechanics and Engineering, vol. 18, pp. 1059-1061, 1999.

[6] B. S. Guan, "Deformation of Tunnels with Soft Rock masss and its Control," Tunnel Construction, vol. 31, no. 1, p. 17, 2011.

[7] R. W. Chen, J. S. Yao, and Z. C. Dong, "Application of pipe roof in highway tunnel portal," China Water Transport, vol. 12, no. 10, pp. 224-225, 2012.

[8] D. Gou, J. Yang, and G. Zhang, "Deformation monitoring and mechanical behaviors of pipe-roof in shallow tunnels," Chinese Journal of Rock Mechanics and Engineering, vol. 26, no. 6, pp. 1258-1264, 2007.

[9] J. J. Zheng, R. J. Zhang, and Q. N. Yang, "Mechanical mechanism of pipe roofs with variable coefficient of subgrade reaction in shallow tunnels," Chinese Journal of Geotechnical Engineering, vol. 31, no. 8, pp. 1165-1171, 2009.

[10] H. T. Wang, J. Q. Jia, and S. Yu, "Mechanical behavior and parameter optimization of pipe roof reinforcement applied in tunnel," China Journal of Highway and Transport, vol. 23, no. 4, pp. 78-83, 2010.

[11] Z. Zhang, H. Li, H. Liu, G. Li, and X. Shi, "Load transferring mechanism of pipe umbrella support in shallow-buried tunnels," Tunnelling and Underground Space Technology, vol. 43, pp. 213-221, 2014.
[12] S. D. Chang, Research on Pre-brace Mechanism of Pipe Umbrella Method [Ph.D. thesis], Southwest Jiaotong University, Chengdu, China, 1999.

[13] H. Wang and J. Jia, "Analytical Method for Mechanical Behaviors of Pipe Roof Reinforcement," in Proceedings of the 2008 International Conference on Information Management, Innovation Management and Industrial Engineering (ICIII), pp. 352357, Taipei, Taiwan, December 2008.

[14] J. Li, Z. Tan, Y. Yu, and L. Ni, "Analysis of deformation monitoring and mechanical behaviors of big pipe-roof for shallowburied large-span tunnel to underpass highway," Journal of Rock Mechanics and Engineering, vol. 30, no. 1, pp. 3002-3008, 2011.

[15] C. Yoo and H.-K. Shin, "Deformation behaviour of tunnel face reinforced with longitudinal pipes-laboratory and numerical investigation," Tunnelling and Underground Space Technology, vol. 18, no. 4, pp. 303-319, 2003.

[16] "Numerical analysis for umbrella arch method in shallow large scale excavation in weak rock," Tunnelling and Underground Space Technology, vol. 19, no. 4-5, p. 500, 2004.

[17] C. Ng, H. Huang, and G. Liu, Geotechnical Aspects of Underground Construction in Soft Ground, CRC Press, 2008.

[18] V. Gunther and S. Wulf, "Optimization of excavation and support in pipe roof supported tunnel sections," Tunnelling and Underground Space Technology, vol. 21, no. 3-4, 2006.

[19] S.-H. Zhou, "Principles of pipe roof applied to shallow-buried tunnels in soft ground," Yanshilixue Yu Gongcheng Xuebao/ Chinese Journal of Rock Mechanics and Engineering, vol. 24, no. 14, pp. 2565-2570, 2005.

[20] M. Hisatake and S. Ohno, "Effects of pipe roof supports and the excavation method on the displacements above a tunnel face," Tunnelling and Underground Space Technology, vol. 23, no. 2, pp. 120-127, 2008.

[21] J.-H. Shin, Y.-K. Choi, O.-Y. Kwon, and S.-D. Lee, "Model testing for pipe-reinforced tunnel heading in a granular soil," Tunnelling and Underground Space Technology, vol. 23, no. 3, pp. 241-250, 2008.

[22] A. R. Shahani, M. M. Shodja, and A. Shahhosseini, "Experimental investigation and finite element analysis of fatigue crack growth in pipes containing a circumferential semi-elliptical crack subjected to bending," Experimental Mechanics, vol. 50, no. 5, pp. 563-573, 2010.

[23] Y. Luo, J. Chen, P. Huang, M. Tang, X. Qiao, and Q. Liu, "Deformation and mechanical model of temporary support sidewall in tunnel cutting partial section," Tunnelling and Underground Space Technology, vol. 61, pp. 40-49, 2017.

[24] D. M. Gou, Deformation Test and Working Mechanism Research of pipe-roof in Double-arch Tunnel under the Existing Highway [M.S. thesis], Changsha University of Science and Technology, Changsha, China, 2007. 


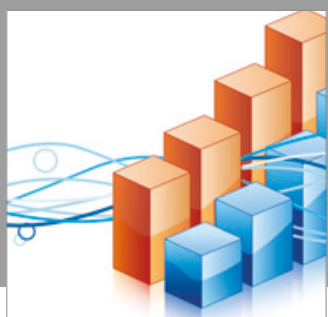

Advances in

Operations Research

vatersals

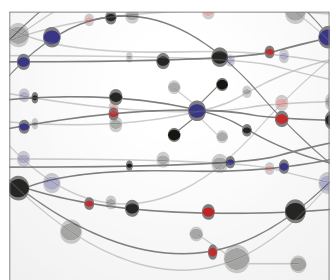

\section{The Scientific} World Journal
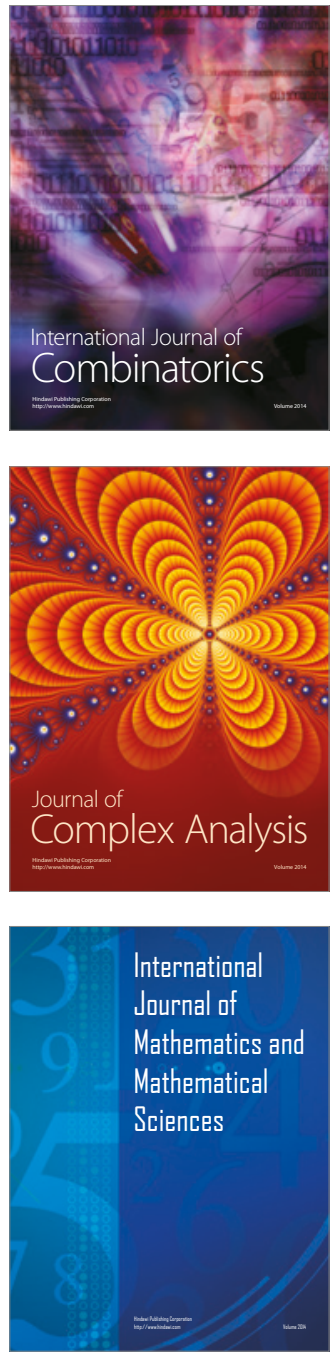
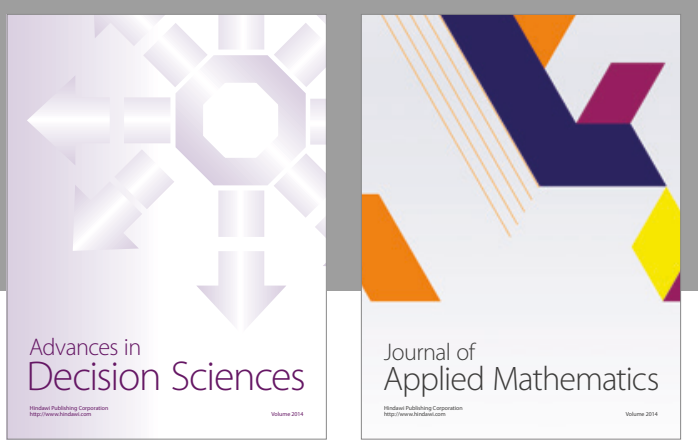

Algebra

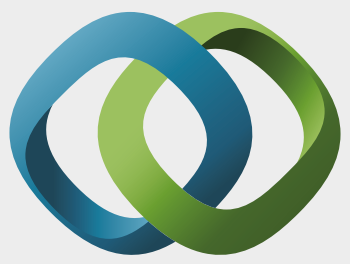

\section{Hindawi}

Submit your manuscripts at

https://www.hindawi.com
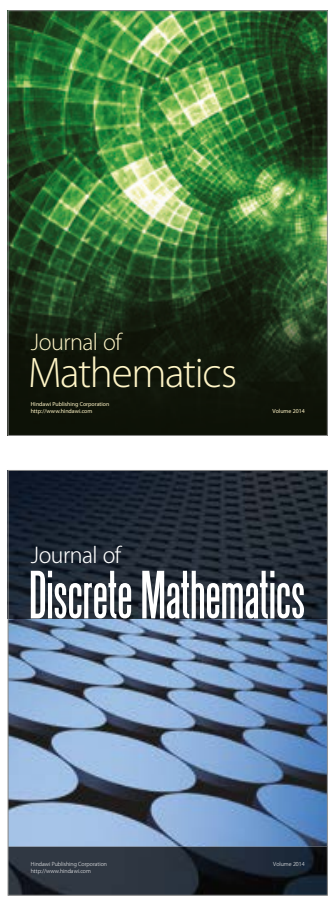

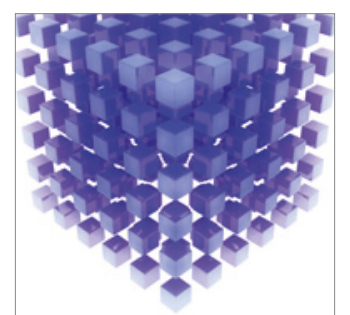

Mathematical Problems in Engineering
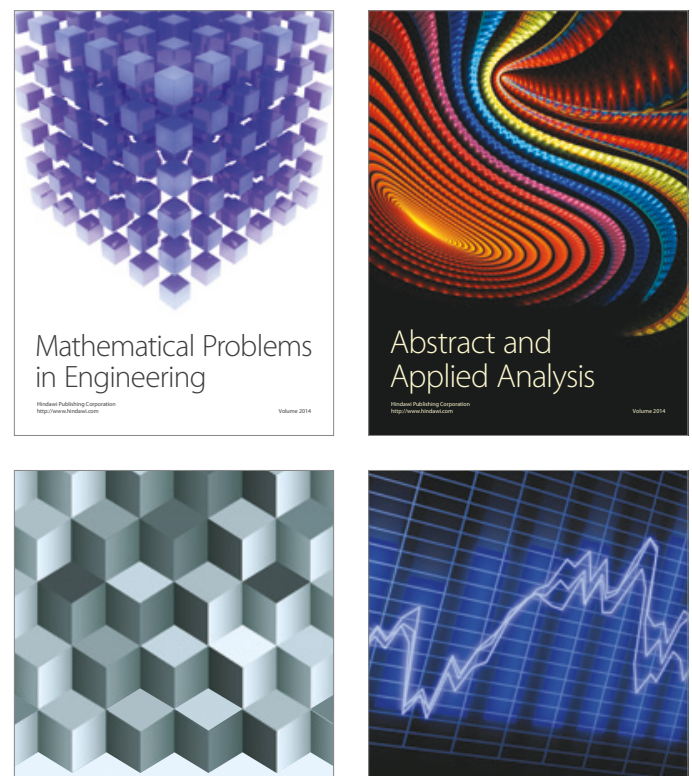

Journal of

Function Spaces

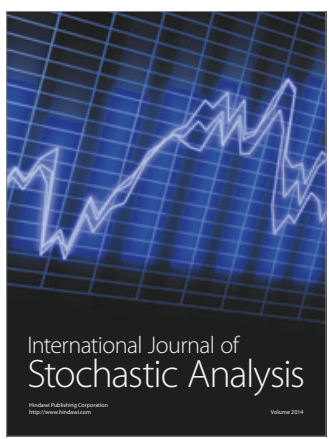

Probability and Statistics
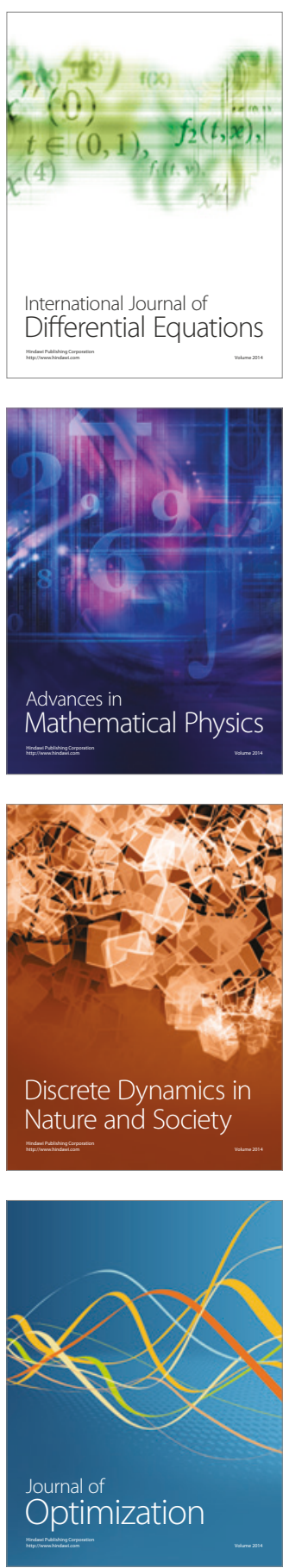